\title{
PARTIAL CHARACTERIZATION OF URINARY ADRENOCORTICAL STEROIDS IN ADRENAL HYPERPLASIA ${ }^{1}$
}

\author{
By WALTER R. EBERLEIN AND ALFRED M. BONGIOVANNI
}

(From the Department of Pediatrics, University of Pennsylvania, and the Endocrine Division, Children's Hospital of Philadelphia, Philadelphia, Pa.)

(Submitted for publication December 13, 1954; accepted April 6, 1955)

Following the demonstration by Wilkins, Lewis, Klein, and Rosenberg (1) that cortisone controls the clinical manifestations and abnormal laboratory findings in virilizing adrenal hyperplasia, Bartter, Albright, Forbes, Leaf, Dempsey, and Carroll (2) postulated a deficient synthesis of "sugar hormone" (17-hydroxycorticosterone, Compound F) in this disease, reasoning from the unusual response of such patients to the administration of adrenocorticotropin (ACTH). This hypothesis has been supported by the demonstration of low blood levels of 17-hydroxylated-corticosteroids ("Porter-Silber chromogens") in untreated patients with adrenal hyperplasia and the usual failure of these levels to rise, following administration of ACTH $(3,4)$. The discovery that, routinely, large quantities of pregnane-3 $\alpha$, $17 \alpha, 20 \alpha$-triol are excreted in the urine of patients with virilizing adrenal hyperplasia (5) has suggested a possible site of the metabolic block in the synthesis of Compound F.

The present studies were undertaken to characterize the corticosteroids excreted in the urine in adrenal hyperplasia, in an attempt to define more precisely the specific defect in steroid biosynthesis.

\section{METHODS}

Twenty-four-hour collections of urine from normal control subjects and from patients with adrenal hyperplasia were investigated in the following manner:

Urine for 17-ketosteroid determinations was hydrolyzed first with beta-glucuronidase 2 and manually extracted with ether; the remaining urine was continuously extracted at room temperature with ether for 36 hours after the addition of 10 volumes per cent $(v / v)$ of 40 per cent sulfuric acid. The combined extracts were fractionated on alumina columns (6) and suitable frac-

1 This work was made possible by a research grant (A-619 R) from the Division of Research Grants and Fellowships, of the National Institutes of Health, United States Public Health Service.

2 "Ketodase," Warner-Chilcott Co. tions were submitted to infra-red spectrophotometric analysis.

The level of urinary neutral 17-ketosteroids produced by bismuthate oxidation ("17-ketogenic steroids") was determined according to the method of Brooks and Norymberski (7).

The quantities of pregnane-3 $\alpha, 17 \alpha, 20 \alpha$-triol were determined in urine hydrolyzed with beta glucuronidase 2 and chromatographed on alumina according to the method of one of the authors (5).

Crude extracts of urine hydrolyzed with beta glucuronidase were chromatographed on florisil (8). The fraction eluted with 25 per cent methanol in chloroform was examined by the following techniques: a) The phenylhydrazine-sulfuric acid method of Porter and Silber $(9)$; b) periodate oxidation for the simultaneous determination of formaldehydogenic and acetaldehydogenic steroids $(10)$; c) phosphomolybdate method of Heard and Sobel (11); d) blue tetrazolium method of Chen, Wheeler, and Tewell (12); e) 2,4-dinitrophenylhydrazine method of Gornall and Macdonald (13).

Urines collected from patients during therapy with cortisone were obtained two weeks to six months following the introduction of the intramuscular administration of Compound $\mathrm{E}$ acetate in doses ranging from 25 to $75 \mathrm{mg}$. given every third day. In each case, the specimen studied was obtained at a time when the total urinary 17-ketosteroids were significantly depressed (1).

Each of the methods described is designed to estimate the quantities of steroids with functional groups as follows. The determination of 17-ketosteroids formed by bismuthate oxidation measures only those compounds with 17,20-dihydroxy, 21 methyl groupings. The phenylhydrazine-sulfuric acid method which determines socalled "Porter-Silber chromogens," measures 17,21-dihydroxy-20-carbonyl side-chains only. Periodate oxidation of urine residues releases formaldehyde from those compounds with a 21-hydroxy group having either a 20 -hydroxy or 20 -carbonyl substituent, regardless of the presence or absence of a 17-hydroxyl function. Periodate oxidation will release acetaldehyde only from steroids with 17,20-dihydroxy, 21-methyl side-chains and hence has the same significance as the 17-ketogenic compounds indicated by bismuthate oxidation. Both the phosphomolybdate and blue tetrazolium techniques measure reducing substances or steroids with an alpha-ketolic sidechain, although the former will also react with molecules possessing an alpha-beta unsaturated system in ring $\mathrm{A}$. The reagent, 2,4-dinitrophenylhydrazine, reacts with various carbonyl functions on the molecule, resulting in the 
formation of complexes showing various maxima between 400 to $500 \mathrm{~m} \mu$, depending on the number and location of such groupings, as described by Gornall and Macdonald (13).

\section{PAPER CHROMATOGRAPHY}

Twenty-four-hour collections of urine from a normal control subject, a patient with Cushing's syndrome, and a patient with untreated adrenal hyperplasia were extracted at neutral $\mathrm{pH}$, and again after glucuronidase hydrolysis, with chloroform. The separate washed extracts were fractionated on florisil columns, as above, and applied to paper. The solvent systems modified after Bush (14) were: Benzene: 50 per cent methanol (B5) ; iso-octane-toluene: 70 per cent methanol $\left(E_{1}\right)$; and iso-octane: 90 per cent methanol $\left(\mathrm{E}_{2}\right)$. Chromatograms were equilibrated at $32^{\circ}$ and developed at room temperature for 3 to 12 hours. The positions of Cpd. F, Cpd. E, pregnane-3 $\alpha, 11 \beta, 17 \alpha, 21$-tetrol-20-one (tetrahydro-F), and pregnane-3 $\alpha, 17 \alpha, 21$-triol-11, 20-dione (tetrahydro-E) were recognized by scanning chromatograms under ultraviolet light and staining central strips with a methanolic-sodium hydroxide solution of triphenyltetrazolium hydrochloride (TPZ), permitting simultaneous detection of reducing steroids, steroids with the dihydroxyacetone side chain (15), and others with the $\Delta 4-3$-keto configuration of Ring A (16). The eluted areas were dried, acetylated, and rechromatographed in the slower systems $E_{1}$ and $E_{2}$ against standards acetylated in the same manner. Final identification rested on these criteria: Mobility of the free compound and its acetate compared to standards on the same chromatogram; the reactions with $\mathrm{TPZ}$ and $\mathrm{NaOH}$; the fluor- escence on paper of $\mathrm{Cpd}$. F treated with concentrated sulfuric acid (17); the blue color given by Cpd. E treated with iodine-potassium iodide (17); the fluorescent reactions of tetrahydro- $F$ and tetrahydro- $E$ treated with 15 per cent phosphoric acid (18); the spectra of the four acetates in sulfuric acid compared to those of pure compounds reported in the literature $(17,19)$.

\section{RESULTS}

Figure 1 illustrates a typical chromatographic study of the neutral 17-ketosteroids excreted by patients with adrenal hyperplasia, before and during treatment with cortisone. It is clear that not only is the total amount of 17 -ketosteroids elevated prior to treatment but that the quantities of 11oxygenated-17 ketosteroids, identified as 11-ketoetiocholanolone and 11-hydroxyandrosterone by infra-red analysis, are disproportionately increased. In this laboratory the 11-oxygenated compounds were found to constitute about 10 per cent of the total neutral 17-ketosteroids excreted by adult male and female controls and 18 to 25 per cent of the total in individuals with adrenal hyperplasia.

The results of bismuthate oxidation are indicated in Figure 2 for six patients with untreated adrenal hyperplasia, compared to nine normal controls. The 24-hour excretion of pregnane- $3 \alpha$,

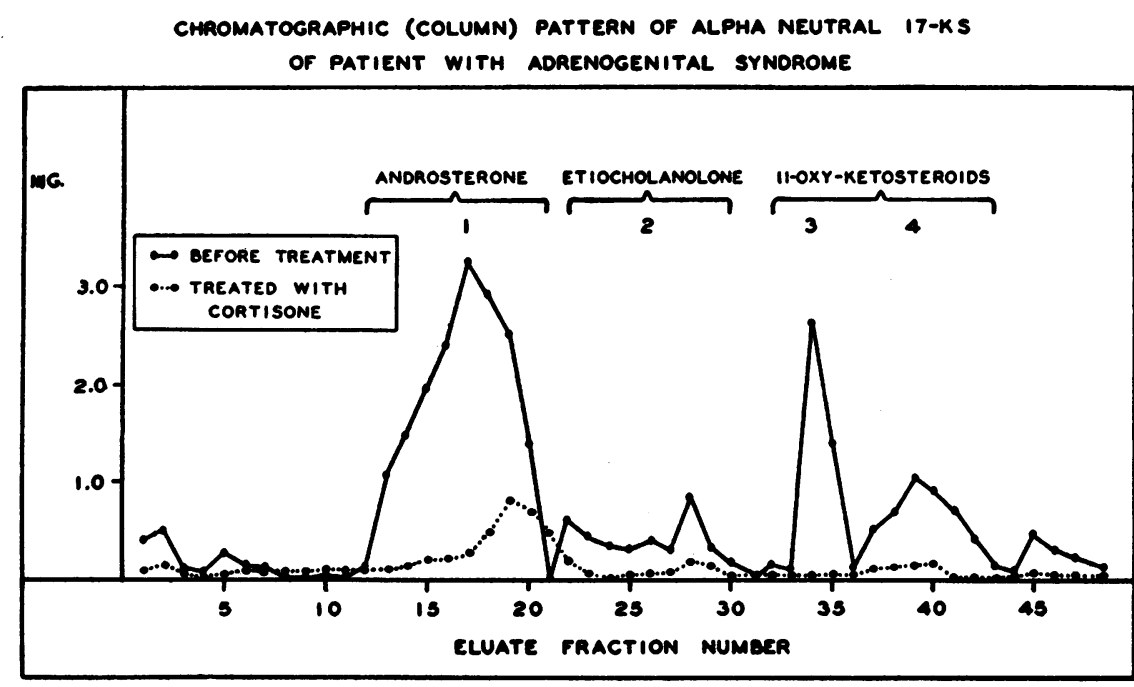

FIG. 1.

The ordinate indicates milligrams of $17-$ ketosteroids per fraction and the abscissa, the individual fractions in order of their elution from the column. The solid line illustrates the results before treatment and the dotted line during treatment with cortisone. 


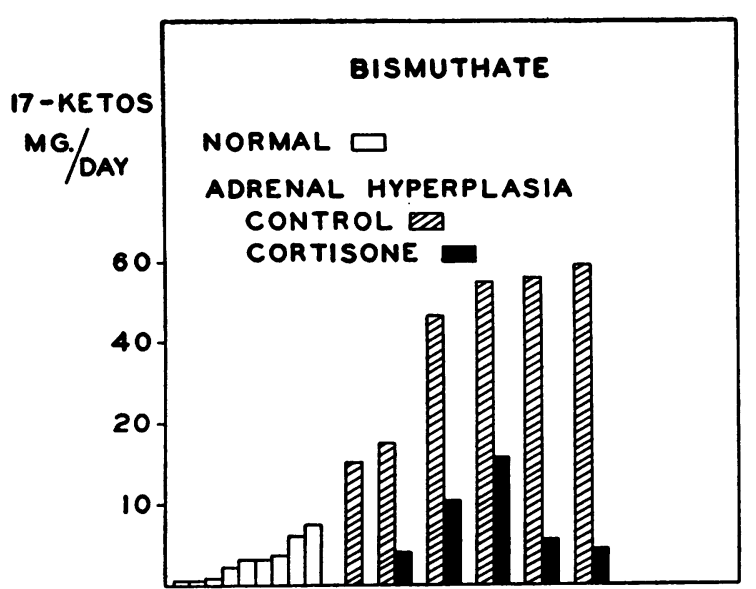

Fig. 2. Twenty-Four-Hour ExCretion IN THE Urine OF 17-Ketosteroids Liberated By Bismuthate Oxidation.

The first 4 "normal" columns and the first 2 "adrenal hyperplasia" columns represent children under the age of nine years. The black columns represent the excretion of these substances during the administration of cortisone.

$17 \alpha, 20 \alpha$-triol is indicated in similar fashion in Figure 3.

Table I lists the results of the various assay methods applied to the steroid fractions obtained from florisil columns. The fractions employed were free of 17-ketosteroids but contained crystalline mixtures of several $\mathrm{C}-21$ steroids. It is evident that the amount of acetaldehydogenic steroids excreted in adrenal hyperplasia is more than 10 times the amount found in the urine of normal controls. These patients also excrete

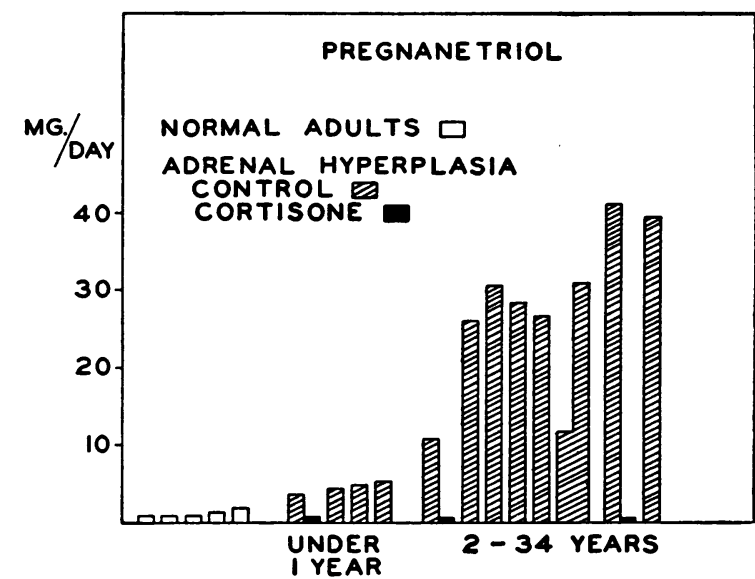

Fig. 3. Twenty-Four-Hour Excretion of PregNane- $3 \alpha, 17 \alpha, 20 \alpha$-Triol in Five Normal Adults, Contrasted with Children and Adults with Adrenal HYPERPLASIA

The suppressed excretion during cortisone treatment is indicated for two individuals.

greater than normal quantities of material detected by the phosphomolybdate reagent.

Figures 4 and 5 illustrate in condensed form the results of a series of 27 chromatograms run on extracts of unhydrolyzed and glucuronidase-hydrolyzed urine from a patient with adrenal hyperplasia, compared to a normal control subject and an individual with Cushing's syndrome. No Compound $\mathrm{F}$ or Compound $\mathrm{E}$ was detected in the unhydrolyzed extract of the patient with adrenal hyperplasia: 30 liters of urine from another patient so studied also contained no detectable

TABLE I

Twenty-four-hour excretion of corticosteroids in urine*

\begin{tabular}{|c|c|c|c|c|c|c|}
\hline \multirow[b]{2}{*}{ Corticosteroid assay method } & \multicolumn{3}{|c|}{ Normal } & \multicolumn{3}{|c|}{ Adrenal hyperplasia } \\
\hline & $\begin{array}{c}\text { No. } \\
\text { subjects }\end{array}$ & $\begin{array}{c}\text { Average } \\
\text { mg. }\end{array}$ & $\begin{array}{c}\text { Range } \\
m g .\end{array}$ & $\begin{array}{l}\text { No. } \\
\text { subjects }\end{array}$ & $\begin{array}{c}\text { Average } \\
\text { mg. }\end{array}$ & $\begin{array}{c}\text { Range } \\
m g .\end{array}$ \\
\hline $\begin{array}{l}\text { Phenylhydrazine }{ }^{-} \\
\text {Phosphomolybdate } \dagger \\
\text { Blue Tetrazolium } \\
\text { 2,4-Dinitrophenylhydrazine }\end{array}$ & $\begin{array}{l}7 \\
7 \\
4 \\
5\end{array}$ & $\begin{array}{r}8.5 \\
13.0 \\
6.5 \\
8.8\end{array}$ & $\begin{array}{l}3.8-13.1 \\
5.5-24.4 \\
2.9-9.0 \\
2.5-18.4\end{array}$ & $\begin{array}{l}7 \\
7 \\
4 \\
8\end{array}$ & $\begin{array}{r}6.1 \\
29.7 \\
7.7 \\
4.5\end{array}$ & $\begin{array}{c}3.8-8.6 \\
19.8-44.0 \\
5.0-10.6 \\
1.8-11.8\end{array}$ \\
\hline $\begin{array}{l}\text { Formaldehydogenic } \\
\text { Acetaldehydogenic } \neq\end{array}$ & $\begin{array}{l}8 \\
7\end{array}$ & $\begin{array}{l}m c g . \\
374 \\
179\end{array}$ & $\begin{array}{c}m c g . \\
210-671 \\
50-456\end{array}$ & $\begin{array}{l}8 \\
7\end{array}$ & $\begin{array}{l}m c g . \\
371 \\
2,014\end{array}$ & $\begin{array}{c}\text { mcg. } \\
235-618 \\
1,249-3,244\end{array}$ \\
\hline
\end{tabular}

* Comparison is made of the urinary excretion by normal individuals and untreated patients with virilizing adrenal hyperplasia, of corticosteroids measured by the procedures described. These are to be contrasted with the findings obtained by paper chromatography (Figures 4 and 5) as described in the text.

$\dagger$ Calculated as milligrams of Cpd. E.

$\ddagger$ Micrograms of formaldehyde or acetaldehyde released by periodate oxidation. 
amount of these substances. Although tetrahydro-E was present in the hydrolyzed extract of this patient, the amount was small compared to the normal.

The results are in contrast to the findings in Table I that urine residues from patients with virilizing adrenal hyperplasia contain normal quantities of steroids detected by phenylhydrazine, blue tetrazolium and formaldehydogenic methods. Each of the latter methods will measure compounds $\mathrm{E}$ or $\mathrm{F}$ and their reduced derivatives. But in view of the results obtained by paper chromatography, it is apparent that the substances measured by the methods shown in Table $I$ are not Compounds $\mathrm{E}$ or $\mathrm{F}$ or their reduced metabolites, as is the case in the urine of normal individuals. Nonetheless, unidentified 21-hydroxylated steroids are present in the urine of untreated patients with adrenal hyperplasia.

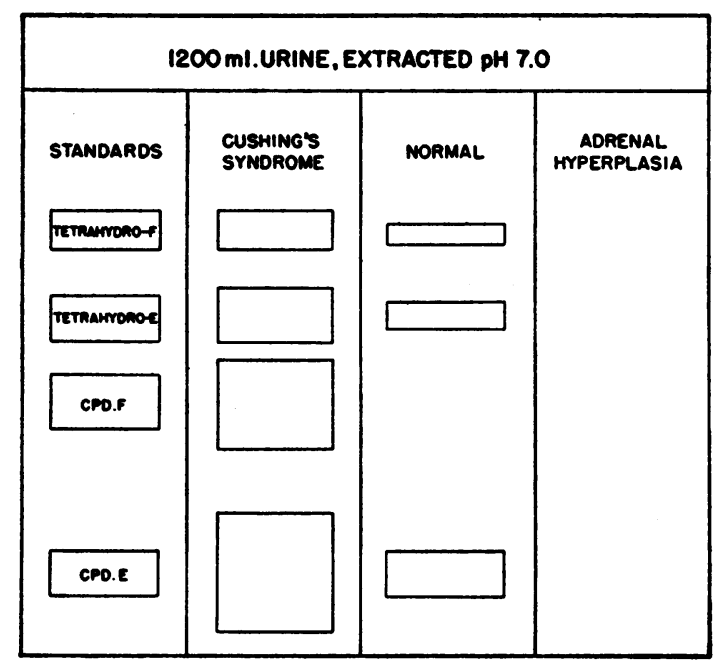

Fig. 4. Condensation of Multiple Paper ChroMatograms RUN ON EXTRACTS OF UNHYDROLYZED URINE from a Normal Subject, a Patient with Cushing's Syndrome, and a Patient with Virilizing Adrenal Hyperplasia to Isolate Compound F, Compound E, and Their Tetrahydro Metabolites

The first column indicates the relative position on the chromatograms of the 4 steroids. The rectangles in columns 2 to 4 indicate the relative amount of the individual steroid excreted, estimated by spot size and staining intensity on the original chromatograms. Note the excess excretion of the 4 steroids in Cushing's syndrome and the complete absence of all in adrenal hyperplasia.

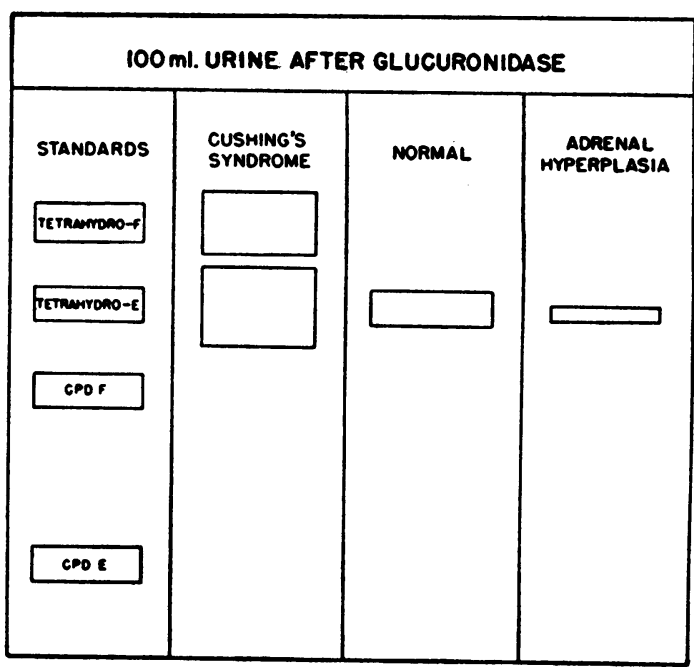

Fig. 5. Condensation of Multiple Chromatograms of Glucuronidase-Hydrolyzed URINe afTER INITIAL Extraction at Neutral pH

Patients and symbols as in Figure 4. Note the small excretion of tetrahydro- $E$ in adrenal hyperplasia, the excessive amount of the same steroid in Cushing's syndrome.

\section{DISCUSSION}

The present investigation of the excretion of Compound $F$, Compound $E$, and their known endmetabolites, tetrahydro- $F$ and tetrahydro- $E$, studied by means of paper chromatography, firmly supports the theory that there is a deficient synthesis of Compound $\mathrm{F}$ in adrenal hyperplasia. At the same time, and in agreement with previous studies on the response of the blood "PorterSilber chromogen" levels to ACTH administration (4), the findings indicate that at least some of these patients can synthesize a small amount of Compound $F$, evidenced by the excretion of a small amount of tetrahydro-E derived from Compound F.

The most characteristic, and hence diagnostic, laboratory finding in virilizing adrenal hyperplasia remains the excretion of large amounts of pregnane-3 $\alpha, 17 \alpha, 20 \alpha$-triol in the urine. This steroid and its recently isolated relative, pregnane$3 \alpha, 17 \alpha, 20 \alpha$-triol-11-one (20), appear to account for the excessive amounts of 17 -ketosteroids liberated by bismuthate oxidation and for the large amounts of acetaldehydogenic steroids detected 
by periodate oxidation in the urine of patients with virilizing adrenal hyperplasia. These results are interpreted to indicate a block in the synthesis of Compound $F$, according to the scheme of Hechter, Zaffaroni, Jacobsen, Levy, Jeanloz, Schenker, and Pincus (21), at some point between 17-hydroxyprogesterone and Compound F, since pregnane- $3 \alpha, 17 \alpha, 20 \alpha$-triol is probably a degradation product of 17-hydroxyprogesterone $(22,23)$.

The results of the various methods used in this study to characterize the corticosteroids excreted in adrenal hyperplasia do not specifically indicate the nature of the defect in Compound $F$ synthesis. According to Hechter's scheme, based upon adrenal perfusion experiments, cholesterol, under the stimulus of $\mathrm{ACTH}$, is converted via pregnenolone into progesterone, which is then successively hydroxylated at carbons 17,21 , and 11 to yield Compound F. It has been shown that adrenal tissue contains enzymes capable of introducing hydroxyl groups into suitable substrates at these three positions in vitro $(24,25)$, although none of these enzymes has as yet been isolated in a pure state. It has already been shown that endogenous ACTH production is high in virilizing adrenal hyperplasia (26), hence one cannot incriminate the absence of an adequate stimulus to Compound $F$ production. Judging from the present study, there is no deficiency of the enzyme which regulates 17-hydroxylation. The excretion of normal quantities of steroids possessing an alpha-ketolic side chain, measured by formaldehyde liberation, as well as the blue tetrazolium and Porter-Silber methods, does not readily suggest a deficiency of a 21 -hydroxylating enzyme. Nor does the presence in the urine of large amounts of 11-oxygenated-17-ketosteroids and of pregnanetriol-11-one point to the lack of an 11-hydroxylating enzyme.

Indeed, in crude extracts of urine from patients with adrenal hyperplasia one can detect normal or excessive amounts of steroids, which in the aggregate possess all the necessary molecular configurations of Compound $F$ itself. Unidentified steroids unsaturated in Ring $\mathrm{A}$ are demonstrable on paper chromatograms and presumably account for the high levels detected with the phosphomolybdate reagent.
The possibility of an abnormal metabolism of pre-formed Compound $F$ may be ruled out by the ease with which small doses of Compound $F$ or $E$ reverse the clinical and chemical abnormalities found in the untreated disease. In addition, Compound $\mathrm{E}$ administered to patients with the disease causes the expected increased excretion in the urine of its known end-metabolite, tetrahydro- $\mathrm{E}$ (27).

Since it appears that the adrenal in this disease can synthesize 17-hydroxyprogesterone, as measured by excessive pregnane- $3 \alpha, 17 \alpha, 20 \alpha$-triol excretion, but cannot produce an adequate amount of Compound F, a deficiency in the enzymes concerned with hydroxylation either at carbon 11 or at carbon 21 might be postulated. The present study offers several objections to the theory of " $11 \beta$-hydroxylase" deficiency in adrenal hyperplasia. Since 11-hydroxylation follows 21-hydroxylation (21), one would not expect a block at this site to lead to the marked excretion of pregnane-3 $\alpha, 17 \alpha, 20 \alpha$-triol but rather of 21 -hydroxylated steroids, such as 17-hydroxy-11-desoxycorticosterone and its reduced derivative, which should be measurable as alpha-ketolic steroids both in blood and urine. The latter compounds have not so far been detected in the urine or blood of patients with virilizing adrenal hyperplasia.

Another objection to " $11 \beta$-hydroxylase" lack is the excess excretion of 11-oxygenated steroids which occurs. In respect to this, however, in adrenal perfusion experiments, but not in studies using adrenal homogenates, some 11-hydroxylation of 21-desoxy steroids, such as progesterone, can occur (21). This suggests that in the intact adrenal there may be normally two enzyme systems concerned with $11 \beta$-hydroxylation, one dependent upon, and the other independent of, prior hydroxylation at carbon 21 . If this is true, the 11-oxygenated steroids excreted in adrenal hyperplasia might derive primarily from 21-desoxy precursors through the action of the latter enzyme.

Dorfman (28) has suggested a deficiency of a 21-hydroxylating enzyme in adrenal hyperplasia. The theory is compatible with the high excretion of pregnane- $3 \alpha, 17 \alpha, 20 \alpha$-triol in the urine and the low levels of Porter-Silber chromogens in the blood. The present study reveals that pa- 
tients with this disease excrete approximately the same amount of alpha-ketolic (i.e., 21-hydroxylated) steroids as do normal individuals, and that most of these steroids detected with the PorterSilber reagent are hydroxylated at carbon 17 , although some may have 16-hydroxyl groups (29). Since endogenous ACTH production is high, the amount of alpha-ketolic steroids excreted may be relatively low. But it is difficult to explain why, in the presence of more than adequate amounts of enzymes capable of inducing hydroxylation at carbon 11, the adrenal cortex is unable to synthesize more respectable quantities of Compound $\mathrm{F}$ from precursors already oxygenated at $\mathrm{C}-17$ and C-21. In other words, the amount of Compound $F$ and its metabolites constitutes a significantly smaller proportion of the total alpha-ketolic steroids excreted in the urine of subjects with this adrenal disorder than in normal controls.

The present study, therefore, does not support the theory of either a single " $11 \beta$-hydroxylase" or "21-hydroxylase" deficiency in adrenal hyperplasia, reasoning from the current concepts of steroid biosynthesis in the adrenal cortex. The presumed inborn error of metabolism is apparently more complicated and may well involve a combination of enzymes and their cofactors. Work in progress in this laboratory, including final identification of the alpha-ketolic steroids excreted in the urine, may help to clarify the underlying disturbance of Compound $\mathrm{F}$ synthesis.

\section{SUMMARY}

A study, utilizing both paper and column chromatographic techniques, revealed an abnormally low excretion of Compound $F$ and its metabolites in the urine of patients with adrenal hyperplasia. This strongly supports the concept of a deficient synthesis of Compound $F$ by the diseased adrenal cortex. The characteristic excretion of pregnane-3 $\alpha, 17 \alpha, 20 \alpha$-triol in large quantities suggests a deficient conversion of 17-hydroxyprogesterone into Compound F. Large amounts of steroids oxygenated at $\mathrm{C}-11$ and at C-17 and "normal" quantities of 21-hydroxylated steroids were detected in the urine of several affected individuals. The nature of the underlying enzymatic defect in the synthesis of Compound $F$ in this disease awaits precise definition.

\section{Addendum}

A patient with congenital adrenal hyperplasia complicated by hypertension, since studied, excreted in the urine predominantly tetrahydro-S (pregnane-3 $\alpha, 17 \alpha, 20$ triol-20-one, confirmed by infra-red analysis), a finding hitherto unreported in this disease. Complete absence in the urine of the normal 11-oxygenated C-21 and 17ketosteroids suggests " $11 \beta$-hydroxylase" deficiency in this form of the disease. (Eberlein, W. R., and Bongiovanni, A. M., J. Clin. Endocrinol. \& Metab., Submitted for publication.)

\section{ACKNOWLEDGMENTS}

The authors acknowledge with pleasure the helpful suggestions of Doctors Lawson Wilkins and Nathan Talbot. The infra-red analyses were performed through the kindness of Doctor Seymour Lieberman. Samples of pure steroids were generously supplied by Doctors John Schneider, Hirsch Sulkowitch, Harold Mason, The G. D. Searle Company, The Squibb Institute for Medical Research and Merck and Company.

\section{REFERENCES}

1. Wilkins, L., Lewis, R. A., Klein, R., and Rosenberg, $E$., The suppression of androgen secretion by cortisone in a case of congenital adrenal hyperplasia. Bull. Johns Hopkins Hosp., 1950, 86, 249.

2. Bartter, F. C., Albright, F., Forbes, A. P., Leaf, A., Dempsey, E., and Carroll, E., The effects of adrenocorticotropic hormone and cortisone in the adrenogenital syndrome associated with congenital adrenal hyperplasia: An attempt to explain and correct its disordered hormonal pattern. J. Clin. Invest., 1951, 30, 237.

3. Ely, R. S., Kelley, V. C., and Raile, R. B., Studies of 17-hydroxycorticosteroids in children. I. Peripheral blood levels in health and disease. J. Pediat., 1953, 42, 38.

4. Bongiovanni, A. M., Eberlein, W. R., and Cara, J., Studies on the metabolism of adrenal steroids in the adrenogenital syndrome. J. Clin. Endocrinol. \& Metab., 1954, 14, 409.

5. Bongiovanni, A. M., and Clayton, G. W., Jr., A simplified method for the routine determination of pregnanediol and pregnanetriol in urine. Bull. Johns Hopkins Hosp., 1954, 94, 180.

6. Dingemanse, E., Huis in't Veld, L. G., and HartoghKatz, S. L., Clinical method for the chromatographic-colorimetric determination of urinary 17ketosteroids. II. Normal adults. J. Clin. Endocrinol. \& Metab., 1952, 12, 66.

7. Brooks, C. J. W., and Norbymberski, J. K., The oxidation of corticosteroids with sodium bismuthate. Biochem. J., 1953, 55, 371.

8. Sandberg, A. A., Nelson, D. H., Glenn, E. M., Tyler, F. H., and Samuels, L. T., 17-hydroxycorticosteroids and 17-ketosteroids in urine of human sub- 
jects: Clinical application of a method employing $\beta$-glucuronidase hydrolysis. J. Clin. Endocrinol. \& Metab., 1953, 13, 1445.

9. Porter, C. C., and Silber, R. H., A quantitative color reaction for cortisone and related 17,21-dihydroxy20-ketosteroids. J. Biol. Chem., 1950, 185, 201.

10. Cox, R. I., A method for the quantitative determination in urinary extracts of $\mathrm{C}_{21}-17: 20$-dihydroxy-21methylsteroids. Biochem. J., 1952, 52, 339.

11. Heard, R. D. H., and Sobel, H., A colorimetric method for the estimation of reducing steroids. J. Biol. Chem., 1946, 165, 687.

12. Chen, C., Wheeler, J., and Tewell, H. E., Jr., Methods of estimation of adrenal cortical steroids with tetrazolium salts. J. Lab. \& Clin. Med., 1953, 42, 749.

13. Gornall, A. G., and Macdonald, M. P., Quantitative determination of the steroid hormones with 2,4dinitrophenylhydrazine. J. Biol. Chem., 1953, 201, 279.

14. Bush, I. E., Methods of paper chromatography of steroids applicable to the study of steroids in mammalian blood and tissues. Biochem. J., 1952, 50, 370.

15. Axelrod, L. R., A specific test differentiating between $\alpha$-ketol and dihydroxy-acetone groups of $\mathrm{C}_{21}$ steroids on paper chromatograms. J. Am. Chem. Soc., 1953, 75, 4074.

16. Bush, I. E., and Sandberg, A. A., Adrenocortical hormones in human plasma. J. Biol. Chem., 1953, 205, 783.

17. Zaffaroni, A., and Burton, R. B., Identification of corticosteroids of beef adrenal extract by paper chromatography. J. Biol. Chem., 1951, 193, 749.

18. Neher, R., and Wettstein, A., Uber Steroide. Farbreaktionen mit Steroiden, insbesondere Corticosteroiden, im Papierchromatogramm. Helvet. chim. acta, 1951, 34, 2278.
19. Bernstein, S., and Lenhard, R. H., The absorption spectra of steroids in concentrated sulfuric acid. I. Method and data. J. Org. Chem., 1953, 18, 1146.

20. Finkelstein, M., Euw, J. V., and Reichstein, T., Isolierung von $3 \alpha, 17,20 \alpha$-trioxy-pregnanon-(11) aus pathologischem menschlichem Harn. Helvet. chim. acta, 1953, 36, 1266.

21. Hechter, O., Zaffaroni, A., Jacobsen, R. P., Levy, H., Jeanloz, R. W., Schenker, V., and Pincus, G., The nature and the biogenesis of the adrenal secretory product. Rec. Prog. Hormone Res., 1951, 6, 215.

22. Mason, H. L., and Kepler, E. J., Isolation of steroids from the urine of patients with adrenal cortical tumors and adrenal cortical hyperplasia: A new 17-ketosteroid, androstane-3 $\alpha, 11$-diol-17-one. J. Biol. Chem., 1945, 161, 235.

23. Bongiovanni, A. M., Unpublished data.

24. Hayano, M., Dorfman, R. I., and Yamada, E. Y., The conversion of desoxycorticosterone to glycogenic material by adrenal homogenates. J. Biol. Chem., 1951, 193, 175.

25. Plager, J. E., and Samuels, L. T., Enzyme system involved in the oxidation of carbon-21 in steroids. Federation Proc., 1952, 11, 383.

26. Sydnor, K. L., Kelley, V. C., Raile, R. B., Ely, R. S., and Sayers, G., Blood adrenocorticotrophin in children with congenital adrenal hyperplasia. Proc. Soc. Exper. Biol. \& Med., 1953, 82, 695.

27. Eberlein, W. R., Unpublished data.

28. Dorfman, R. I., The metabolism of adrenal steroids in Adrenal Cortex. Transactions of the Fifth Conference, 1953, New York, Josiah Macy, Jr. Foundation, 1954, p. 27.

29. Mattox, V. R., Mason, H. L., and Albert, A., Isolation of a sodium-retaining substance from beef adrenal extracts. Proc. Staff Meet., Mayo Clin., 1953, 28, 569. 